\title{
A MULTIMODALIDADE SOB O VIÉS TEXTUAL: ANÁLISE DE UM GÊNERO
}

\section{The multimodality under the textual point of view: analysis of a gender}

\author{
Ana Cristina Carmelino* \\ Maria da Penha Pereira Lins**
}

\begin{abstract}
RESUMO
Este artigo pretende contribuir com o processo de leitura e construção de sentido de textos multimodais à luz dos pressupostos teóricos da Linguística Textual de base sociocognitiva e interacional. Para isso, toma-se como objeto de análise o guia ilustrado, um gênero multimodal veiculado na revista humorística MAD, periódico impresso e publicado no Brasil desde 1974. Embora a multimodalidade constitua um traço inerente às práticas comunicativas, tendo em vista o fato de que toda produção textual está inserida em multissistemas, mesclando em sua constituição elementos linguísticos e não linguísticos, a análise desse tipo de texto ainda constitui desafio para os estudos textuais contemporâneos. Partindo dessas considerações, objetiva-se não apenas mostrar estratégias sociocognitivas e textuais que viabilizam a leitura de textos multimodais - como é o caso da inferenciação, referenciação e organização tópica -, mas também evidenciar como a Linguística Textual tem ampliado seus conceitos e colaborado para a leitura de diferentes produções textuais.
\end{abstract}

Palavras-chave: multimodalidade; Linguística Textual; guia ilustrado.

* Universidade Federal de São Paulo e Programa de Pós-Graduação em Linguística da Universidade Federal do Espírito Santo.

** Universidade Federal do Espírito Santo. 


\begin{abstract}
This paper contributes to the process of reading and constructing meaning from multimodal texts based on theoretical elements of Textual Linguistics of sociocognitive and interactional basis. For this work, it is taken as the object of analysis an illustrated guide, a multimodal gender aired on MAD humor, magazine printed and published in Brazil since 1974. Though multimodality constitutes an inherent trait of the communicative practices, in view of the fact that all textual production is embedded in multi-system, blending into its constitution linguistic and non-linguistic elements, the analysis of this type of text is still a challenge for contemporary textual studies. Based on these considerations, the objective is not just to demonstrate sociocognitive and textual strategies that enable reading of multimodal texts - such as the inferential act, the referential process and topical organization -, but also to show how Textual Linguistics has expanded its concepts and contributed with reading different textual productions.
\end{abstract}

Keywords: multimodality; Textual Linguistics; illustrated guide.

\title{
1. A multimodalidAdE COMO TRAÇO INERENTE ÀS PRÁtICAS COMUNICATIVAS
}

As formas de interação na sociedade sempre foram realizadas por meio de linguagens diferentes e associadas. Como destaca Dionísio (2005), nas práticas comunicativas verbais orais ou escritas, dificilmente se usa apenas um modo de representação. Às palavras integram-se os gestos, as entonações, as imagens, as animações, as tipografias. A esses elementos podemos acrescentar outros, como cor, textura, tamanho da letra, layout, que podem ser de extrema relevância para se processar o sentido dos textos.

Às produções textuais constituídas por diversos tipos e modos representacionais, ou seja, por elementos linguísticos e não linguísticos, tem se atribuído o nome de multimodais. As ações multimodais não constituem uma novidade; na verdade, elas são inerentes às práticas comunicativas. No entanto, o termo multimodalidade é relativamente atual. Pode-se dizer que começou a circular no Brasil a partir do final do século 20 por influência dos estudos de Kress e Van Leeuwen (1996).

Considerando-se não apenas os novos contornos que a linguagem verbal vem assumindo na sociedade contemporânea, mas também a predominância do uso de imagens (fotos, figuras, desenhos), Kress e Van Leeuwen, baseados nos pressupostos teóricos da Semiótica Social e na gramática sistêmico-funcional de Halliday (1994), propõem uma gramática (Gramática de Design Visual - GDV) como resposta à necessidade de desenvolver mé- 
todos de análise textual que contemplem (e descrevam) todos os modos de representação (recursos semióticos) que entram na configuração de um texto.

$\mathrm{Na}$ busca em aprofundar os processos de leitura das imagens, compostas por signos heterogêneos, Kress e Van Leeuwen (1996) propõem o conceito de signo social, o qual vincula-se a um complexo ideológico do qual as pessoas fazem parte.

O método de leitura das imagens proposto por Kress e Van Leeuwen (1996, 2001) é a transcodificação da forma visual para a verbal. Algumas categorias de análise sugeridas pelos estudiosos mostram-se significativas para a leitura de imagens estáticas. Tais dados explicam o fato de grande parte das pesquisas sobre multimodalidade atualmente feitas no Brasil adotarem o aparato teórico-metodológico desses autores (cf. ARAÚJO, 2011).

Dentre as categorias sugeridas, destacam-se a distância social (que se refere aos planos fechado, médio e aberto, conforme a imagem esteja localizada mais ao fundo ou mais à frente), a perspectiva (ângulo enfocado, se frontal ou oblíquo), a modalidade (que concerne à cor, à iluminação, ao brilho) e a saliência (tamanho da imagem). No que diz respeito à articulação entre os signos, Kress e Van Leeuwen $(1996,2001)$ ressaltam a relação entre o elemento dado (trecho à esquerda) e o novo (trecho à direita) e a presença das personagens, que observam o leitor ou são observadas por ele.

Embora o olhar para o que se chama de multimodalidade tenha ganhado maior saliência neste século, a preocupação em se entender os diferentes signos (recursos semióticos, linguagens) e a forma como eles se associam sempre estiveram presentes nos estudos sobre a linguagem em diversas abordagens teóricas. Uma referência a estudiosos/estudos que trazem contribuições a respeito de como os signos de natureza distinta, especialmente os visuais (como as imagens), podem ser lidos, cite-se o Grupo $\mu$ (1993).

Esse grupo propõe um tratado do signo visual que se insere na perspectiva da retórica geral (estrutural). Ao registrar que nem sempre é possível sintetizar uma figura por meio de uma palavra ou expressão, o Grupo $\mu$ revela não haver supremacia do signo verbal sobre os de ordem visual. Nessa ótica, os signos devem ser analisados em pé de igualdade.

Outro ponto interessante do tratado é que a análise visual não pode se resumir aos elementos figurativos. Para os pesquisadores do Grupo, o signo visual, que deve ser reconhecido por suas características e pelas relações que mantém com outras unidades visuais que integram o todo, agrega dois elementos: o icônico e o plástico.

O signo icônico seria a reconstrução ou transformação do referente (real). Assim, ao representar uma ideia, o produtor (desenhista, pintor, designer gráfico) estabelece analogia com o real, mas não produz o real. o signo plástico compreende o que o Grupo $\mu$ chama de textura (metaforicamente, 
remete ao grau da superfície de um objeto e à espécie de sensação tátil que produz visualmente), cor (dominância, luminosidade e saturação) e forma.

As considerações tecidas deixam claro que, priorizando determinado signo em suas análises, os teóricos sempre souberam da existência e importância de diferentes signos presentes nas atividades comunicativas. Logo, estas sempre estiveram imersas em um ambiente multimodal. Nesse sentido, o sistema linguístico (o mais prestigiado nos estudos) é apenas um dos modos de constituição dos textos que materializam as ações sociais.

A Linguística Textual, que se preocupa com as atividades verbais (escritas e orais), vem buscando incorporar a seus estudos enunciados com elementos não linguísticos, no intuito de ampliar mecanismos usados no processamento sociocognitivo e interacional dos textos. Cabe, no entanto, salientar que essa tarefa ainda constitui desafio para os estudos textuais contemporâneos.

A mudança, nessa perspectiva, começa com a revisão do próprio conceito de texto, que é alargado. A ideia inicial parte de Marcuschi (2008), que propõe, com base em Beaugrande (1997), que texto é um "evento construído numa orientação de multissistemas, ou seja, envolve tanto aspectos linguísticos como não linguísticos no seu processamento (imagem, música)"; fato que o torna, em geral, "uma produção multimodal" (p. 80).

Nessa mesma esteira, procurando integrar as linguagens verbais e não verbais, Cavalcante (2012) refina ainda mais o conceito de texto, ao dizer que se trata "de um evento comunicativo em que estão presentes os elementos linguísticos, visuais e sonoros, os fatores cognitivos e vários aspectos, (...) um evento de interação entre locutor e interlocutor, os quais se encontram em um diálogo constante" (p. 20). Nessa ótica, o texto a ser analisado pode ser apenas verbal (escrito ou oral), apenas visual (considerando-se elementos de ordem plástica ou icônica) ou multimodal - produção híbrida que contempla diferentes modalidades em sua composição.

Partindo dessas considerações e levando em conta o fato de que a Linguística Textual sempre ofereceu categorias para se ler produções verbais (escritas e orais), não se busca, aqui, apresentar uma contribuição teórica nova, mas, sim, mostrar categorias de análise desse arcabouço teórico-metodológico que viabilizam a leitura de textos multimodais, bem como evidenciar como a Linguística Textual brasileira vem trabalhando com esse tipo de produção. Para isso, toma-se como objeto de análise um gênero multimodal publicado na revista humorística MAD, o guia ilustrado, que nada mais é do que uma sátira aos guias ilustrados em geral. 


\section{GUIA ILUSTRADO: CONTEXTUALIZAÇÃo DO GÊNERO MULTIMODAL EM ANÁLISE}

O guia, geralmente, consiste em uma publicação com instruções ou orientações sobre algum assunto particular ou serviço, cujo propósito é "guiar" a realização de uma ação ou várias ações (a partir de normas, dicas ou conselhos), prescrever comportamentos ou ensinar sobre algo específico.

Caracterizado por Carmelino (2013), o guia ilustrado é um subtipo do protótipo guia, visto que apresenta características próprias, como a abordagem humorística e a composição multimodal. A última propriedade do gênero é a que justifica tomá-lo como objeto de ilustração e análise neste artigo. Para isso, veja-se o exemplo que segue.

Figura 1 - Guia MAD para passar no vestibular (FÉLIX; MINAMI, 2013, p. 26-27)

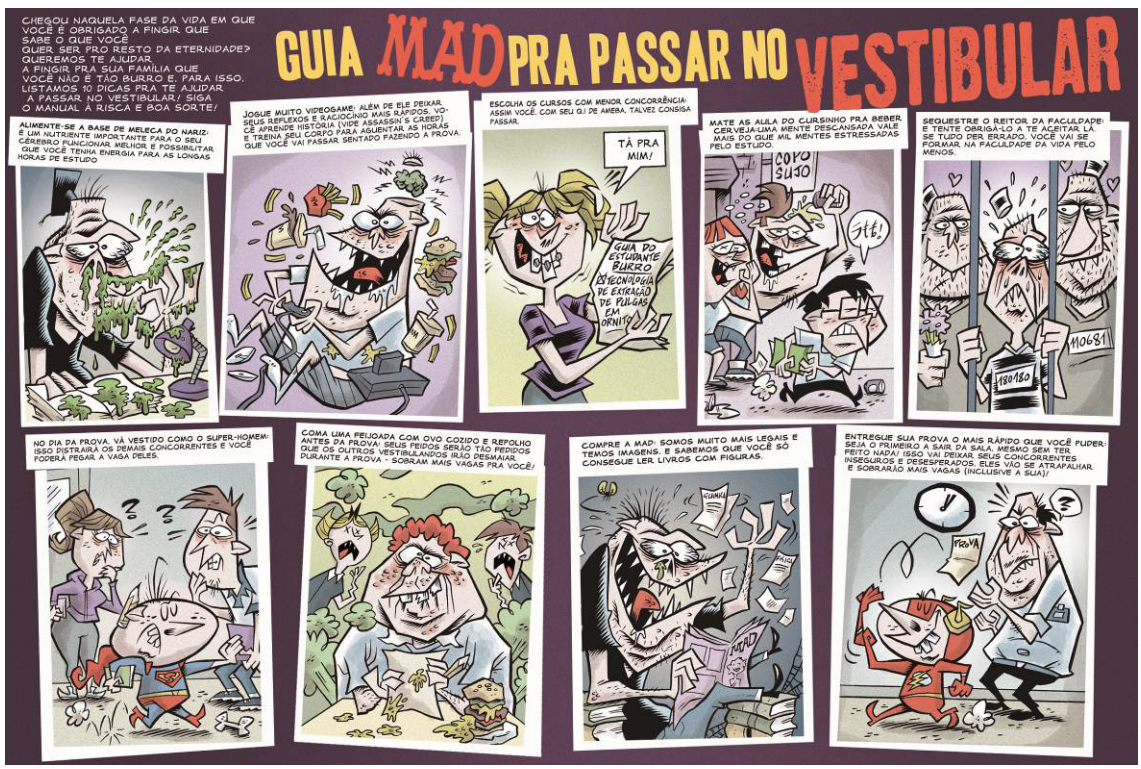

O "Guia MAD para passar no vestibular" (FÉLIX; MINAMI, 2013, p. 26-27), de autoria de Chico Félix (arte) e Renata Minami (texto), faz parte da seção FUDEST (nítida referência à FUVEST - Fundação Universitária para o Vestibular). Em sua constituição, observa-se uma pequena introdução (acima, no canto esquerdo da p. 26) e nove orientações distribuídas ao longo de duas páginas (cinco, na parte superior das folhas, e quatro, na parte inferior).

As especificidades do guia ilustrado são depreendidas do suporte onde o gênero é publicado: a revista de/com quadrinhos MAD. Considerando- 
-se que, para se ler qualquer gênero, é importante que se conheça o suporte que o veicula, tecem-se aqui alguns esclarecimentos sobre a MAD.

Criada em 1952, nos EUA, a revista tornou-se famosa por satirizar aspectos da cultura popular por meio de um humor tosco e subversivo. $O$ sucesso desse periódico, que se dirige especialmente aos jovens, fez com que ele ganhasse versões em vários países ao longo do tempo. No Brasil, ele começou a ser publicado em 1974.

Um estudo feito por Carmelino (2014) revela que a série atual da MAD, publicada desde 2008 pela editora Panini, apresenta em sua composição diferentes textos, os quais se referem ou não aos conhecidos gêneros dos quadrinhos. Esta é a razão de se classificar a revista como de/com quadrinhos.

Quadrinhos ou história em quadrinhos (HQs) são narrativas (humorísticas ou não) que articulam elementos verbais e não verbais e que, comumente, apresentam-se configuradas em (sequências de) quadro(s). De acordo com os estudiosos do assunto, o termo "quadrinhos" consiste em um grande rótulo que abriga diferentes gêneros, identificados a partir de uma linguagem em comum, como é o caso da tira, da charge e do cartum (cf. CAGNIN, 1975, 2003; MENDONÇA, 2003; RAMOS, 2010, 2011).

Em se tratando da revista MAD, pode-se dizer que em seu diversificado repertório genérico encontram-se: os gêneros dos quadrinhos (tira, cartum, charge, HQ), os gêneros que não pertencem aos dos quadrinhos (editorial, carta de leitor, entrevista, slogan) e os gêneros que estabelecem relação de intertextualidade genérica com os quadrinhos (relação híbrida) ou com a linguagem dos quadrinhos, como é o caso do guia ilustrado (cf. CARMELINO, 2014).

O exemplo da Figura 1 esclarece melhor as considerações tecidas. Como se verifica, a configuração das instruções/orientações no formato de quadros, a presença de personagem e de balões de fala são alguns dos recursos que elucidam essa relação híbrida, na qual há uma mescla entre os gêneros. Além disso, vale ressaltar que, embora o guia ilustrado não seja um gênero fixo na revista (como o editorial, a tira, a carta de leitor), ele apresenta uma constância. Dado que o torna, de certa forma, característico da MAD.

Quanto à caracterização do gênero, tomando-se como referencial teórico os pressupostos de Bakhtin (2011) - para quem todo gênero relaciona-se a um campo, tem um conteúdo temático, um estilo e uma construção composicional -, verifica-se que o guia em análise pertence ao campo do humor, visto tratar-se, como já dito, de uma sátira ao gênero "guia ilustrado". A situação social de interação compreende um autor extremamente irreverente (muitas vezes irônico, agressivo e até mesmo tosco) que se dirige diretamente ao leitor jovem da revista, também irreverente. 
A presença do humor pode ser conferida não somente pelas imagens caricatas (que servem ora de ilustração às ações propostas, ora de complementação das informações enunciadas verbalmente), mas também pelo tom de zombaria constante da introdução ("Chegou naquela fase da vida em que você é obrigado a fingir que sabe o que quer ser pro resto da eternidade? Queremos te ajudar a fingir pra sua família que você não é tão burro e, para isso, listamos 9 dicas pra te dar uma mão no vestibular!!! Siga o manual à risca e boa sorte!") e das instruções/orientações.

No guia em questão (Figura 1), por exemplo, uma das orientações é "Escolha os cursos com menor concorrência: assim você, com seu Q.I de ameba, talvez consiga passar" (cena 3). A imagem, que ilustra e complementa o enunciado verbal, apresenta uma vestibulanda (jovem loira, com dois rabos de cavalo no cabelo e aparelhos nos dentes) que fala "tá pra mim!" (balão), ao mostrar uma folha de papel com os seguintes dizeres "Guia do estudante burro", no qual está assinalada a opção "tecnologia de extração de pulgas em ornito".

Figura 2 - Instrução (cena 3) do Guia para passar no vestibular (FÉLIX; MINAMI, 2013, p. 26-27)

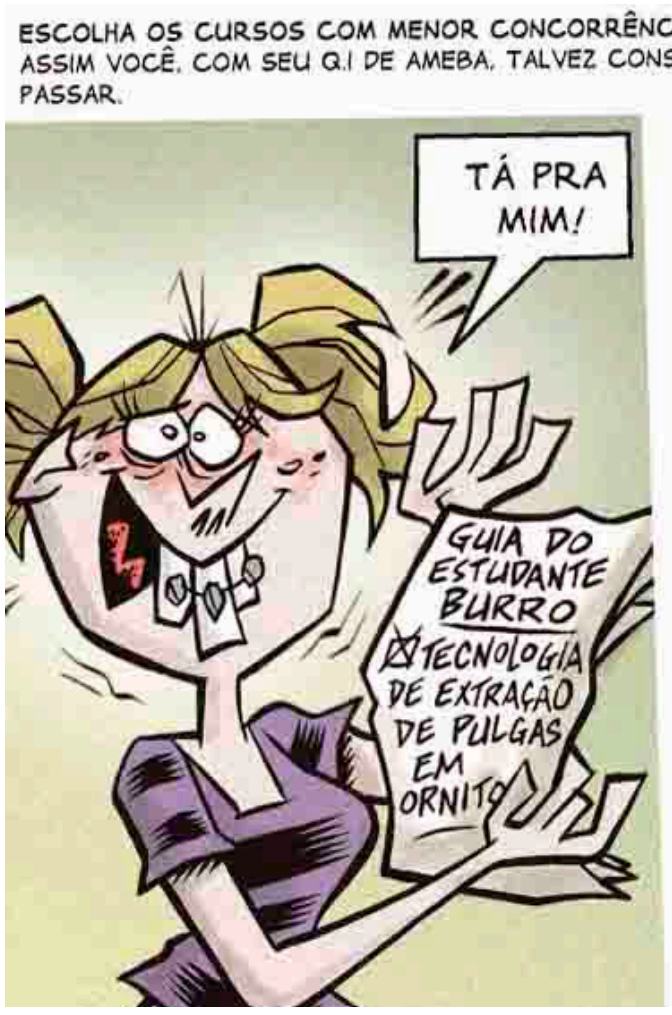


O humor, como se observa na Figura 2, pode ser explicado por alguns elementos: a articulação entre os signos verbais escritos (enunciados) e os signos não verbais (caricatura da vestibulanda), assinalados pelo exagero; o conhecimento prévio de que, para passar no vestibular, muitos estudantes escolhem os cursos menos concorridos; e a quebra de expectativa, quando se apresenta assinalada uma opção de profissão que não existe ("tecnologia de extração de pulgas em ornito").

Em geral, como já foi dito, o propósito comunicativo dos guias é orientar a realização de uma ação ou várias ações a partir de normas, dicas ou conselhos, prescrever comportamentos ou instruir sobre um assunto específico. A relação estabelecida entre os parceiros da interação é, portanto, a de orientar (autor/falante) e ser orientado (leitor/ouvinte). No caso dos guias ilustrados da MAD, as orientações apresentam algumas particularidades:

a) são descabidas: o autor propõe ao leitor uma orientação inapropriada ou mesmo impossível. É o que se vêm em: (i) "Entregue sua prova o mais rápido que puder: seja o primeiro a sair da sala, mesmo sem ter feito nada! Isso vai deixar seus concorrentes inseguros e desesperados, eles vão se atrapalhar e sobrarão mais vagas (inclusive a sua)!" (cena 9) ou (ii) "Alimente-se à base de meleca do nariz: é um nutriente importante para seu cérebro funcionar melhor e possibilitar que você tenha energia para as longas horas de estudo" (cena 1); e

b) revelam, de forma chistosa, comportamentos e práticas sociais arraigadas na sociedade. É o caso de: (i) "Mate as aulas do cursinho pra beber cerveja: uma mente descansada vale mais do que mil mentes estressadas pelo estudo" (cena 4) ou (ii) "Escolha os cursos com menor concorrência: assim você, com seu Q.I de ameba, talvez consiga passar" (cena 3).

A estrutura composicional dos guias ilustrados apresenta uma relação direta com a revista de/com quadrinhos MAD. Nesse sentido, além de multimodais, já que mesclam elementos linguísticos e não linguísticos, eles são híbridos, porque contemplam características do gênero guia e dos gêneros dos quadrinhos.

Quanto ao gênero guia, nota-se a presença do discurso instrucional (de aconselhamento), caracterizado pela sequência textual injuntiva ${ }^{1}$, na qual as orientações, sempre numa interlocução direta com o leitor, aparecem

1 As sequências textuais são unidades estruturais relativamente autônomas, organizadas em fases que podem combinar uma ou mais proposições. Cada sequência constitui uma forma de composição com uma função específica, que pode ser: narrar (narrativa), argumentar (argumentativa), descrever (descritiva), explicar (explicativa), orientar passos em uma instrução (injuntiva) e apresentar uma conversa (dialogal). A sequência injuntiva faz o destinatário agir de certo modo ou em certa direção, desse modo apresenta uma sucessão de ações instrucionais, realizadas pela presença de formas verbais no imperativo ou infinitivo (cf. BRONCKART, 1999). 
marcadas pelo uso de verbos no modo imperativo e orações exclamativas. É o que se vê em na orientação constante da cena 7: "Coma uma feijoada com ovo cozido e repolho antes da prova: seus peidos serão tão fedidos que os outros vestibulando irão desmaiar durante a prova - sobram mais vagas pra você!"(grifos nossos).

No que concerne aos gêneros dos quadrinhos, observa-se no guia o predomínio do discurso humorístico e da sequência textual narrativa ${ }^{2}$; o uso de linguagem que mescla signos verbais escritos e visuais; personagens caricatas; balões que representam falas ou pensamentos; linhas cinéticas que indicam movimento; cor (verde, na meleca do nariz); signos icônicos (abelha, ponto de interrogação); e sinais gráficos que realçam expressões (grifo e negrito em "burro").

Com relação ao estilo, os guias ilustrados da MAD apresentam uma linguagem ultracoloquial (tosca, chula, com gírias), que aproxima intimamente os parceiros da interação. Esses dados podem ser constatados nos exemplos já mencionados, com destaque para o uso de determinados termos ("alimente-se à base de meleca do nariz", "seus peidos serão tão fedidos", "mate as aulas") e para a forma de tratamento ("você, com seu Q.I de ameba”).

Findadas as considerações sobre o gênero guia ilustrado, busca-se, a seguir, mostrar como determinadas categorias textuais e sociocognitivas, dentro do quadro teórico da Linguística Textual brasileira, viabilizam a leitura e a construção de sentido de gêneros multimodais.

\section{GUIA ILUSTRADO: FORMAS DE LER O TEXTO MULTIMODAL À LUZ DOS PRESSUPOSTOS DA Linguística TeXTUAL}

Dois esclarecimentos se fazem necessários no início deste tópico. o primeiro deles é que, por uma questão prática, opta-se por discutir os conceitos teórico-metodológicos da Linguística Textual à medida que eles forem contemplados para explicar a produção do sentido do guia ilustrado. o segundo esclarecimento é que se busca apresentar a análise detalhada de apenas um exemplo de guia ilustrado, cujas características refletem mais comumente esse gênero multimodal. Trata-se de "O guia escolar MAD para evitar bullying", que pode ser visto a seguir.

2 A sequência narrativa, que é sustentada por uma intriga (tensão e resolução de tensão), mobiliza personagens em acontecimento organizado no eixo sucessivo. Caracteriza-se pelas fases: situação inicial, complicação, ações desencadeadas, resoluções, situação final, avaliação e moral. 
Figura 3 - Guia escolar MAD para evitar o Bullying (FÉLIX; NETO, 2010, p. 40-41)

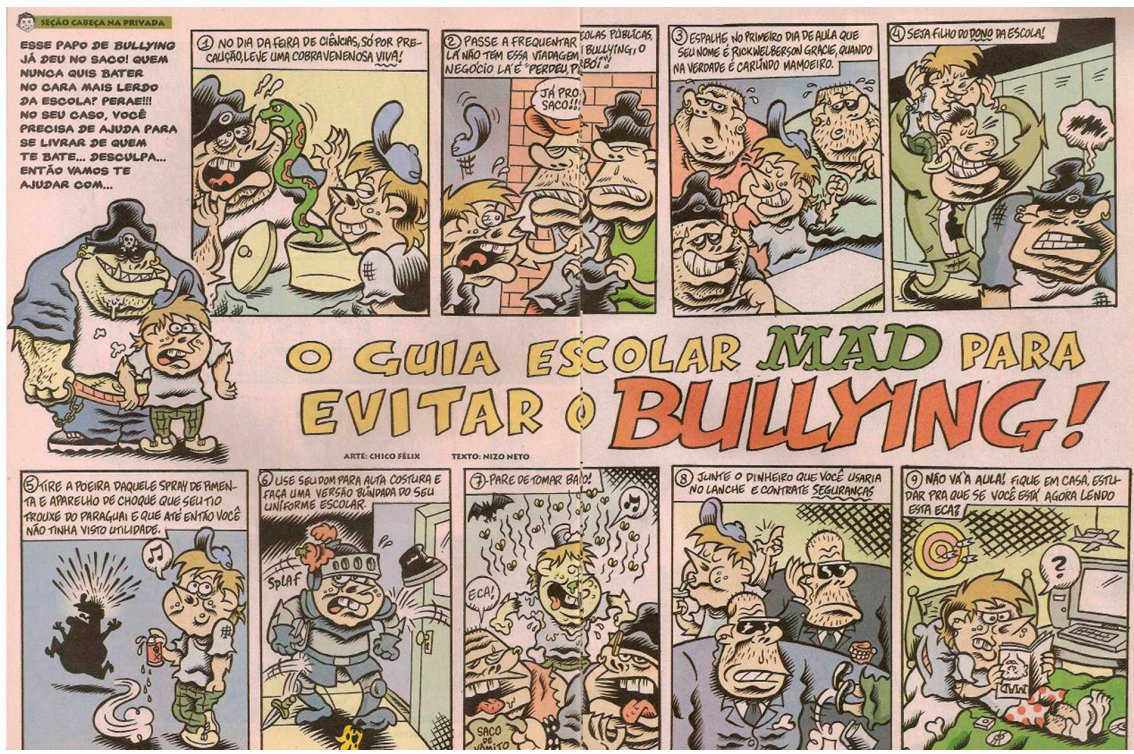

O guia acima, contido na "seção cabeça na privada" da revista MAD, é composto por um título que se destaca no centro das duas páginas, uma introdução (acima, no canto esquerdo da p. 40), uma imagem bem abaixo da introdução (no meio, canto esquerdo da p. 40) e nove orientações ilustradas e enumeradas que se acomodam em quadros dispostos na parte superior e inferior das duas páginas (p. 40-41). Cada uma das orientações constitui uma cena, um acontecimento cômico.

Ainda que não seja uma característica presente em todos os exemplos constantes das edições da revista, pode-se dizer que há uma tendência de os guias da MAD, talvez para conduzir a leitura, distribuírem as instruções enumeradas em uma ou duas páginas.

A produção multimodal, como se observa, é caracterizada pela complementaridade de multissistemas. Há vários signos de natureza diferente que nos saltam aos olhos: além dos signos verbais escritos e de suas diferentes formas expressivas (o tipo, a forma e o tamanho das letras; o uso de negrito e sublinhado), há vários elementos não verbais, como os signos pictóricos (as imagens desenhadas que figuram personagens caricatas e fixas), os signos icônicos (a nota musical e o ponto de interrogação nos balões que, ao representarem uma ideia, buscam estabelecer analogia com o real), os signos plásticos (a cor) e os de contorno (a linha que envolve as instruções 
e os balões). Para que se possa compreender a produção multimodal como um todo, o guia em questão será abordado por partes.

Ao se olhar para o texto, chama a atenção o enunciado central que corresponde ao título. No meio de duas páginas, ele aparece grafado com letras grandes (com destaque maior para a palavra "bullying") e cores distintas: amarelo em "O GUIA ESCOLAR PARA EVITAR O", verde em "MAD", e vermelho em "BULLYING". Segundo se observa, além do azul, são essas as cores que predominam nas imagens que compõem o texto como um todo. Essa leitura leva em conta elementos sígnicos de ordem plástica.

Sabe-se a importância que um signo plástico, como a "cor", pode assumir no arranjo de um texto multimodal. Verifica-se, com exceção de alguns casos - como o vermelho em "bullying", que pode simbolizar a violência, e o verde na cobra que aparece na primeira instrução (cena 1) - que outros elementos ganham maior proeminência na construção do sentido.

Mais relevante que a cor presente no título, por exemplo, é o objeto de discurso principal que o guia instaura, "bullying", e a relação tópica que esse objeto estabelece com o restante dos dados e, em especial, com cada orientação/instrução que aparece emoldurada, conforme se verá.

Desse modo, alude-se a duas categorias textuais de análise da Linguística Textual que, segundo se entende, viabilizam a leitura de textos multimodais: o processo de referenciação (a partir da noção de objeto de discurso) e a organização tópica do texto (a partir da noção de tópico discursivo). Tratar-se-á, primeiramente, da referenciação que, compreendida como forma de produção e retomada de objetos do discurso, consiste em um fenômeno textual-discursivo relevante para a produção/compreensão dos sentidos.

O processo de referenciação - concebido numa perspectiva sociocognitiva e interacional da linguagem, como o fazem Mondada (2001, 2005), Mondada e Dubois (1995) e Apothéloz e Reichler-Béguelin (1995), da qual partem os estudiosos da Linguística Textual no Brasil (cf. KOCH, 2002, 2005, 2009; MARCUSCHI, 2008; CAVALCANTE, 2011, 2012, entre outros) é tido como uma operação efetuada pelos sujeitos sociais, à medida que o discurso se desenvolve. É aquilo que designamos, representamos, sugerimos quando criamos uma situação discursiva referencial com uma determinada finalidade. Trata-se de uma operação discursivamente produzida, na qual os sujeitos constroem objetos de discurso.

Os objetos de discurso, nas palavras de Cavalcante (2012, p. 98), consistem em "um objeto, uma entidade, uma representação construída a partir do texto e percebida, na maioria das vezes, a partir do uso de expressões nominais referenciais". Recortados pelas dimensões perceptiva, cognitiva e subjetiva que se cria no universo textual, os objetos de discurso "são dinâmicos, uma vez introduzidos, podem ser modificados, desativados, reativados, 
transformados, recategorizados, construindo-se ou reconstruindo-se, assim, o sentido, no curso da progressão textual” (KOCH, 2005, p. 80-1).

De acordo com Koch (2002, 2005, 2009), na produção de um texto é possível considerar as seguintes estratégias de referenciação: i) construção/ativação, quando o objeto de discurso, ainda não mencionado, é introduzido no texto (lembrando que a introdução pode ser ancorada ou não ancorada ${ }^{3}$ ) ; ii) reconstrução/reativação, quando o objeto de discurso já introduzido é reativado, mantendo-se em foco; e iii) desfocalização/desativação, quando um novo objeto de discurso é introduzido, passando a ocupar a posição focal. Tais estratégias possibilitam a progressão textual, que se efetiva especialmente pela oscilação de movimentos prospectivos (realizados pela catáfora) e retrospectivos (realizados pelas anáforas). Para a autora, a progressão textual "se dá com base no já dito, no que será dito e no que é sugerido, que se codeterminam progressivamente" (KOCH, 2005, p. 85).

o guia ilustrado em questão trata de "bullying". Do inglês bully, que significa "valentão", bullying refere-se a todas as formas de atitudes agressivas - sejam elas físicas ou verbais, intencionais e repetitivas - que ocorrem sem motivação evidente. Por se tratar de um texto humorístico, Nizo Neto introduz verbalmente e também focaliza o objeto de discurso de forma bastante debochada: "Esse papo de bullying já deu no saco! Quem nunca quis bater no cara mais lerdo da escola? Perae!!! No seu caso, você precisa de ajuda para se livrar de quem bate ... Desculpa... Então vamos te ajudar com ... o guia escolar MAD para evitar o Bullying!” (p. 40).

Note-se que a construção do sentido humorístico instaurado na introdução deve-se, entre outros recursos, especialmente à forma como o objeto de discurso é categorizado (assunto saturado = "já deu no saco"; prática desejada = "quem nunca quis bater no cara mais lerdo da escola?") e instantanea e contrariamente recategorizado (prática que pode ser evitada, portanto, por extensão, indesejável = "Perae!!!", "Desculpa...", "vamos te ajudar com o guia [...] para evitar o bullying!”).

Se uma das explicações para a produção do humor está na atitude inesperada, na quebra de expectativa, pode-se constatar que a mudança repentina de posição, acaba sendo uma das fontes do humor neste caso. Outro dado que também contribui para a deflagração da comicidade é o fato de

3 A ativação não ancorada é quando se introduz no texto um objeto de discurso totalmente novo; já a ativação ancorada é quando um novo objeto de discurso é introduzido no texto com base em algum tipo de associação com elementos já presentes no cotexto ou no contexto sociocognitivo do locutor. 
se tratar de um assunto sério de forma banal ${ }^{4}$; o que pode ser visto a partir do uso da expressão chula "dar no saco" ("encheu", "saturou”, "cansou”).

Considerando-se, pelo conhecimento prévio, que o bullying geralmente é exercido por um ou mais indivíduos, cujo objetivo é intimidar ou agredir outra pessoa sem que esta tenha a possibilidade ou capacidade de se defender, bem como que essa prática se dá, comumente, dentro de uma relação desigual de forças ou poder, a imagem logo abaixo do enunciado introdutório não só retoma, coesivamente, o objeto de discurso principal, mas também lhe acrescenta novas informações.

Trata-se de dois indivíduos do sexo masculino. Um deles se posiciona atrás (e bem próximo) do outro. Pelo conjunto de elementos presentes no cotexto, infere-se que sejam dois garotos (ainda que com diferenças visíveis), afinal, o guia é para se evitar bullying escolar (a maior parte das cenas reflete o ambiente escolar). o garoto que está atrás - provavelmente o que pratica bullying - tem quase o dobro do tamanho do da frente; o que já revela uma relação desigual de forças. Além disso, apresenta um perfil de mau. A expressão facial e alguns signos icônicos ajudam na construção dessa metáfora visual, a do estereótipo de valentão: sorriso sarcástico, dentes cerrados, caninos e baba de cachorro, olhos escondidos por um boné com o símbolo de caveira, algemas nas mãos e piercing no nariz. O garoto menor, que está na frente, mostra-se assustado e acuado. Os olhos arregalados e a boca aberta sintetizam a expressão de medo (a vítima teme o agressor). Tais elementos permitem ler que, neste caso, é quem sofre bullying.

Segundo se entende, essa imagem funciona como anáfora encapsuladora ou anáfora definicional visual, uma vez que define/descreve/sintetiza o que vem a ser bullying, objeto de discurso mencionado anteriormente. Desse modo, assume-se que o determinante visual pode ser entendido como uma categoria referencial construída e reconstruída no processo de progressão multimodal. Logo, o verbal escrito e o não verbal se articulam para levar o leitor a construir o sentido de bullying. Por meio da linguagem verbal escrita tem-se a ativação/apresentação do objeto de discurso; por meio da visual, sua caracterização pela retomada. Neste caso, a imagem é fundamental na conformação da construção do sentido do verbal, tendo em vista que ela agrega informações.

4 De acordo com o sociólogo Orson Camargo (2015), os atos de bullying ferem princípios constitucionais - respeito à dignidade da pessoa humana - e ferem o Código Civil, que determina que todo ato ilícito que cause dano a outrem gera o dever de indenizar. O responsável pelo ato de bullying pode também ser enquadrado no Código de Defesa do Consumidor, tendo em vista que as escolas prestam serviço aos consumidores e são responsáveis por atos de bullying que ocorram dentro do estabelecimento de ensino/trabalho. 
Além do processo de referenciação, a partir da construção e reconstrução de objeto de discurso, outras noções mostram-se essenciais à leitura do guia multimodal. Trata-se do conhecimento prévio e da inferência.

Os conhecimentos prévios são os diferentes saberes que os indivíduos têm armazenados na memória e que são acionados no processamento textual. Segundo Koch (2009, p. 22-24), esses conhecimentos não são organizados aleatoriamente, mas em forma de modelos cognitivos, e podem estar relacionados à língua, ao mundo e às práticas interacionais.

Considerando-se que as informações, em diversos níveis, somente são explícitas em parte em um texto, as inferências são estratégias cognitivas por meio das quais o ouvinte ou leitor, partindo da informação veiculada pelo texto e levando em conta o contexto, constrói novas representações mentais (KOCH, 2009). As inferências "funcionam como hipóteses coesivas" na construção do sentido dos textos, como lembra Marcuschi (2008, p. 249).

Assim, se a produção de sentidos de qualquer texto exige do leitor a ativação de conhecimentos prévios, a percepção do que vem a ser um guia cria expectativas que envolvem um saber sobre o gênero: ele deve trazer orientações, prescrições ou instruções sobre algo. O "guia escolar" em questão responde a essa expectativa, trazendo nove orientações ilustradas de como se evitar o bullying. Cada uma das orientações constitui anáforas indiretas. Ou seja, não há no cotexto um antecedente explícito, mas, sim, um elemento de relação que podemos chamar de âncora e que é decisivo para se compreender as instruções/os aconselhamentos/as orientações: trata-se do termo "guia".

Em "Seja o filho do dono da escola!" (cena 4), por exemplo, temos a ativação de um novo objeto de discurso "filho do dono da escola". Trata-se de uma anáfora indireta, tendo em vista que o objeto é constituído não a partir de uma expressão precisa, pontual, mencionada anteriormente, mas com base em inferências ancoradas no contexto, em conhecimentos prévios e em relações semânticas inscritas no enunciado "Guia escolar MAD para evitar o bullying".

Sabe-se que o "dono da escola", por constituir uma autoridade, tem poder para aplicar punições contra qualquer prática ilegal que ocorra na escola. É quem manda. Exige, portanto, respeito. Ser "filho do dono da escola" é uma forma de impedir o bullying. Cumpre salientar que tais conhecimentos prévios são corroborados pelo item não verbal, que encapsula (pela anáfora visual) o que significa ser "filho de dono de escola": o filho do dono da escola está sobre os ombros do pai, quando se depara com a figura de um virtual sujeito causador de bullying (privilégio do filho do dono da escola: estar no colo do pai, sob a proteção do pai). 
Outra categoria de análise da Linguística Textual que permite a construção do sentido do guia ilustrado como um todo - as nove orientações/ instruções ilustradas e articuladas com os demais enunciados presentes em sua composição, a saber, título, introdução e imagem - é a organização tópica.

O tópico discursivo corresponde ao tema central do texto ou àquilo sobre o que se fala (KOCH, 1992). Dois traços básicos definem essa noção: a centração e a organicidade. A centração consiste no "inter-relacionamento entre as unidades de sentido do texto, que convergem para um eixo temático, ou seja, para o tópico central" (CAVALCANTE, 2012, p. 86). A organicidade diz respeito à propriedade que um tópico tem de se relacionar com outros na sequência discursiva.

Convém ainda registrar que a organicidade pode ser vista em dois planos: o vertical e o horizontal. o plano vertical analisa a relação existente entre tópico central e os subtópicos a ele subordinados, o que pode gerar níveis hierárquicos de organização. O plano horizontal ou linear é aquele em que a organização dos tópicos se dá na sequência do desenvolvimento do texto, isto é, na ordem em que os tópicos e subtópicos são apresentados.

Esses dados ficam mais claros quando ilustrados no guia em análise. O tópico discursivo central do "guia para evitar o bullying na escola" é depreendido no título. É a partir dele que todos os demais assuntos (os subtópicos) se relacionam. No que tange à organicidade, que leva à progressão tópica, no plano vertical pode-se observar que estão subordinados ao tópico central: a "apresentação do assunto" (por meio de signos verbais escritos - introdução que se localiza no canto esquerdo, acima da p. 40); a "definição de bullying" (por meio de signos não verbais - imagem que se localiza logo abaixo do enunciado introdutório, no centro esquerdo da $\mathrm{p}$. 40), e as "orientações para evitar o bullying" (nove orientações que mesclam signos verbais escritos e não verbais, sendo que quatro se localizam na parte superior e cinco na parte inferior das p. 40 e 41).

As relações de interdependência entre os níveis hierárquicos de organização tópica (plano vertical) dão origem a quadros tópicos, como podemos ver abaixo.

Figura 4 - Relação do tópico e dos subtópicos no plano hierárquico (vertical)

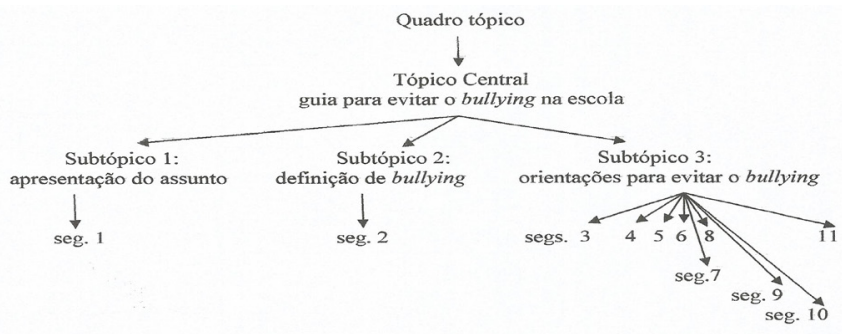


Antes de tratar das relações estabelecidas no plano linear (horizontal), é preciso esclarecer que a manutenção/progressão tópica é realizada por meio de cadeias semântico-lexicais e itens visuais que parecem organizar-se de dois modos particulares: ou sugerindo uma sequência cronológica de um fato em especial ou mediante um conjunto de assuntos relacionados. Esses dois modos de progressão podem ser classificados a partir de uma tipologia maior, elaborada por Danes (apud KOCH, 2002) que, entre outras, evidencia a progressão temática linear e a progressão temática por tema explodido.

No "Guia escolar para MAD para evitar bullying!", a continuidade é feita preferencialmente pela progressão temática por tema explodido em todos os níveis hierárquicos. Para exemplificar, apresenta-se nas figuras abaixo o esquema da cadeia semântico-lexical e dos itens visuais que garantem a continuidade dos subtópicos 1, 2 e 3.

Figura 5 - Relação do tópico e subtópico1 no plano linear (horizontal)

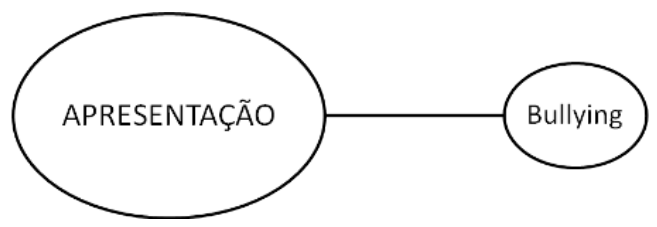

Figura 6 - Relação do tópico e subtópico 2 no plano linear (horizontal)

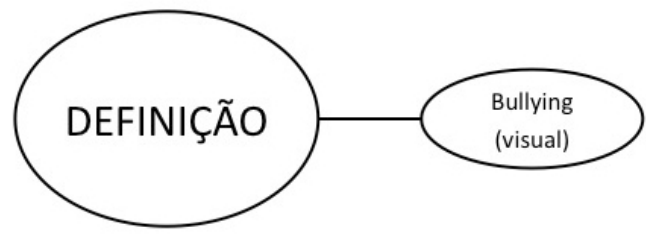

Figura 7 - Relação do tópico e subtópico 3 no plano linear (horizontal)

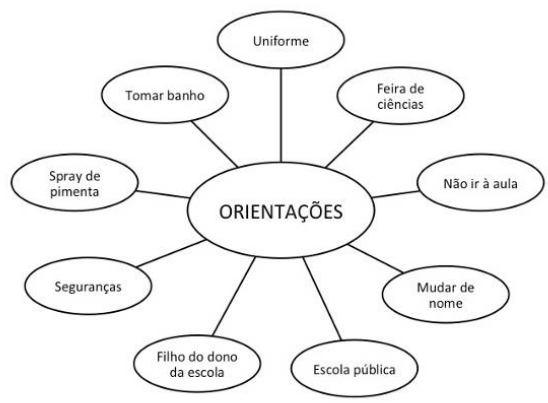


Desse modo, pode-se perceber a organização linear do quadro tópico "Guia escolar para MAD para evitar bullying!" constitui-se de três subtópicos: "apresentação do assunto" (Figura 5), "definição de bullying" (Figura 6) e "orientações para evitar o bullying" (Figura 7).

O subtópico 1 é constituído por um único segmento atualizado em linguagem verbal escrita, cuja cadeia semântico-lexical apresenta o tópico (assunto). O subtópico 2 é constituído por um único segmento atualizado em linguagem não verbal, cujos traços gráficos caricaturais em conjunto com as expressões fisionômicas (de terror e medo) e os signos icônicos (caveira, algemas, baba, entre outras) definem o tópico. O subtópico 3 é constituído de nove segmentos que focam quatro assuntos: escola (seg. 3, 4, 5, 6, 8 e 11), seguranças (seg. 10), tomar banho (seg. 9) e spray de pimenta (seg. 7).

Dos nove segmentos tópicos referentes às orientações, seis desenvolvem o assunto "escola", a saber: "feira de ciências" (seg. 3), "escola pública" (seg. 4), "mudar de nome (no primeiro dia de aula)" (seg. 5), "filho do dono da escola" (seg. 6), "uniforme" (seg. 8) e "não ir à aula" (seg. 11). Essa progressão se inicia por uma continuidade linear entre os quatro primeiros segmentos $(3,4,5$, e 6$)$ e duas descontinuidades que são geradas por inserção: o segmento 7 "spray de pimenta" (inserido entre os segmentos 6 e 8 ) e os segmentos 9 "tomar banho" e 10 "seguranças" (inseridos entre os segmentos 8 e 11).

Convém salientar que, em geral, as orientações encerram o sentido em si, ou seja, cada instrução corresponde a uma cena (acontecimento cômico), cuja leitura não depende da articulação com outras orientações. Uma cena não tem, portanto, sequência em outra cena. Elas mantêm relação com o tópico central, depreendido no título.

No que diz respeito à articulação estabelecida entre a linguagem verbal escrita e a não verbal, pode-se dizer que, em termos de quantidade informacional, o uso das imagens (signos não verbais) no guia ilustrado tende a ser mais recorrente do que o uso dos signos verbais escritos.

Entende-se que a relação entre os signos verbais escritos e não verbais, não só no exemplo em questão, mas em outros guias constantes da revista, funciona como as sequências chamadas de pares adjacentes ${ }^{5}$, tendo em vista que, na parte verbal escrita, tem-se sempre a instrução/orientação por meio do aconselhamento ou ordem e, na parte visual, a concretização

5 O termo par adjacente (ou par conversacional) é uma sequência de dois turnos que coocorrem e servem para a organização local da conversação. Muitas vezes eles representam uma coocorrência obrigatória, dificilmente adiável ou cancelável, como no caso do cumprimento (A: oi; B: oi). Segundo Marcuschi (2003, p. 34-35), os pares adjacentes mais comuns são: pergunta-resposta; ordem-execução; convite-aceitação/recusa, cumprimento-cumprimento, xingamento-defesa/revide, acusação-defesa/justificativa, pedido de desculpa-perdão. 
dessa instrução, ou seja, o cumprimento do conselho ou da ordem. Dessa relação, é nítido que a imagem não assume o papel de mera ilustração da palavra. Entre o verbal e não verbal há, portanto, uma interdependência: os diferentes códigos transmitem ideias que não poderiam ser expressas isoladamente.

Do exposto, demonstra-se o quanto é relevante considerar os elementos não verbais na construção do sentido de textos verbais escritos que os contemplem, bem como entender o texto em um sentido mais amplo, numa orientação de multissistemas, que pode envolver aspectos linguísticos e não linguísticos em seu processamento, como é o caso dos textos multimodais.

\section{Considerações FInAIS}

Ao analisar o gênero multimodal guia ilustrado da revista MAD com base no arcabouço teórico-metodológico da Linguística Textual, este artigo busca não apenas mostrar que determinadas estratégias sociocognitivas e textuais - como é o caso da inferenciação, do conhecimento prévio, da referenciação e da organização tópica - constituem categorias que viabilizam a leitura de produções multimodais, mas também evidenciar como atualmente essa perspectiva teórica vem trabalhando com a leitura desse tipo de texto.

O guia ilustrado em questão é composto pela articulação de signos de diferentes naturezas. Para lê-lo, não é possível desconsiderar esse fato, priorizando, por exemplo, apenas um desses signos, como os elementos linguísticos. Em várias cenas, como se busca destacar, a imagem e outros recursos não linguísticos são de extrema importância para se processar o sentido.

Desse modo, ao admitir a multimodalidade como inerente às práticas comunicativas e alargar o conceito de texto - que passa, então, a ser visto como um lugar em que se concentram ações de natureza multissemiótica, interativa e social, e cujas fronteiras são maleáveis, histórica e socialmente delimitáveis -, a Linguística Textual tem ampliado seus conceitos e contribuído com a leitura de diferentes produções textuais.

\section{REFERÊNCIAS}

APOTHÉLOZ, Denis; REICHLER-BÉGUELIN, Marie-José. Construction de la reference et strategies de designation. In: BERRENDONNER, Alain; REICHLER-BÉGUELIN, Marie-José (orgs.). Du sintagma nominal aux objects de discours. Neuchâtsh: Université de Neuchâtsh, 1995. p. 227-271.

ARAÚJO, Antonia Dilamar. Gêneros multimodais: mapeando pesquisas no Brasil. Linguagem em foco (Revista do Programa de Pós-Graduação em Linguística Aplicada da UECE. Multimodalidade e letramento visual), v. 3, n. 5, p. 23-24. Fortaleza: EdCECE, 2011. 
BAKHTIN, Mikhail Mikhailovich. Gêneros do discurso. In: BAKHTIN, Mikhail Mikhailovich. Estética da criação verbal. Tradução de P. Bezerra. São Paulo: Martins Fontes, 2011. p. 261-306.

BEAUGRANDE, Robert-Alain de. New foundations for a science of test and discourse: cognition, communication, and freedom of access to knowledge and society. Norwood: Alex, 1997.

BRONCKART, Jean-Paul. Atividade de linguagem, textos e discursos: por um interacionismo sócio-discursivo. São Paulo: EDUC, 1999.

CAGNIN, Antonio Luiz. Os quadrinhos. São Paulo: Ática, 1975.

CARMELINO, Ana Cristina. Humor, multimodalidade e hibridismo: elementos característicos do gênero guia. Intersecções, Jundiaí, ano 6, n. 2, p. 68-88, nov. 2013.

. Reflexões sobre a (ir)relevância de categorizar gêneros: em questão certos textos humorísticos. Revista (Con)textos Linguísticos, Vitória, v. 8, p. 141-165, 2014.

CAMARGO, Orson. Bullying. Disponível em: <http://www.brasilescola.com/sociologia/bullying. htm >. Acesso em: 18 nov. 2015.

CAVALCANTE, Mônica Magalhães. Referenciação: sobre coisas ditas e não ditas. Fortaleza: Edições UFC, 2011.

Os sentidos do texto. São Paulo: Contexto, 2012

DIONÍSIO, Ângela Paiva. Gêneros textuais e multimodalidade. In: KARWOSKI, A. GAYDECKZA, B.; BRITO, K. (Orgs.). Gêneros textuais: reflexões e ensino. Rio de Janeiro: Lucerna, 2005. p. 159-177.

FÉLIX, Chico; MINAMI, Renata. Guia MAD para passar no vestibular. MAD, São Paulo, Panini, n. 62, p. 26-27, set. 2013.

FÉLIX, Chico; NETO, Nizo. Guia escolar MAD para evitar o Bullying. MAD, São Paulo, Panini, n. 31 , p. $40-41$, out. 2010

GRUPO $\mu$. Tratado del signo visual: para uma retórica de la imagen. Madrid: Cátedra, 1993.

HALLIDAY, Michael Alexander Kirkwood. An introduction to Functional Grammar. London: Edward Arnold, 1994.

KOCH, Ingedore Villaça Grunfeld. A inter-ação pela linguagem. São Paulo: Contexto, 1992.

. O texto e a construção dos sentidos. 7. ed. São Paulo: Contexto, 2002.

. Desvendando os segredos do texto. 4. ed. São Paulo: Cortez, 2005.

2009.

Introdução à linguística textual: trajetória e grandes temas. São Paulo: Martins Fontes,

KRESS, Gunther; LEEUWEN, Theo van. Reading Images: the grammar of visual design. New York: Routledge, 1996.

Multimodal discourse: the modes and media of contemporary communication. London:

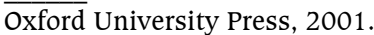

MARCUSCHI, Luiz Antonio. A. Produção textual, análise de gêneros e compreensão. São Paulo: Parábola, 2008.

. Análise da conversação. 5. ed. São Paulo: Ática, 2003.

MENDONÇA, Márcia Rodrigues de Souza. Um gênero quadro a quadro: a história em quadrinhos. In: DIONÍSIO, Ângela Paiva; MACHADO, Anna Rachel Machado; BEZERRA, Maria Auxiliadora. Gêneros textuais \& ensino. Rio de Janeiro: Lucerna, 2003. p. 194-207.

MONDADA, Lorenza. Gestion du topic et organization de la conversation. Cadernos de Estudos Linguísticos, Campinas, n. 41, p. 7-35, 2001. 
A referência como trabalho interativo: a construção da visibilidade do detalhe anatômico durante uma operação cirúrgica. In: KOCH, I. V. G.; MORATO, E.; BENTES, A. C. (Orgs.). Referenciação e discurso. São Paulo: Contexto, 2005. p. 11-31.

MONDADA, Lorenza; DUBOIS, Danièle. Construction des objets de discours et catégorisation: une approche des processus de référenciation. Paris: Travel, 1995.

RAMOS, Paulo Eduardo. A leitura dos quadrinhos. São Paulo: Contextos, 2010.

. Faces do humor: uma aproximação entre piadas e tiras. Campinas: Zarabatana, 2011.

Submetido em: $12 / 05 / 2015$

Aceito em: 25/06/2015 